\title{
Graha Maria Annai Velangkanni sebagai Bentuk Pewartaan Injil secara Inkulturatif di Medan
}

\begin{tabular}{|c|c|}
\hline & $\begin{array}{l}\text { M. Marihot Simanjuntak a,1 } \\
{ }^{\mathrm{a}} \text { Universitas Sanata Dharma Yogyakarta } \\
{ }^{1} \text { marihot.simanjuntak@gmail.com }\end{array}$ \\
\hline $\begin{array}{l}\text { Keywords: } \\
\text { pewartaan Injil, } \\
\text { devosi, } \\
\text { inkulturasi, } \\
\text { Graha Maria } \\
\text { Annai Velangkanni, } \\
\text { Evangelii Gaudium, } \\
\text { ornamen, } \\
\text { simbol. }\end{array}$ & $\begin{array}{l}\text { ABSTRACT } \\
\text { Marian Shrine of Annai Velangkanni, which is located in Sakura III Street } \\
\text { Medan-North Sumatera, actually is a Catholic-church with Hindu-Moghul } \\
\text { architecture. Many people visit this shrine because of its uniqueness, the or- } \\
\text { naments and symbols, and the service of Fr. James Bharataputra, SJ. This } \\
\text { building becomes a precious asset for the Archdiocese of Medan. The aim of } \\
\text { this article is to prove the effectiveness of Marian Shrine of Annai Velangkan- } \\
\text { ni for inculturated evangelization. How can the idea of the founder be under- } \\
\text { stood by the visitors? How can evangelization, inculturation, and devotion be } \\
\text { developed in the Archdiocese of Medan? These questions will be answered by } \\
\text { a field-research. We use mixed method: qualitative and quantitative namely } \\
\text { with depth interviews and questioner. In the light of Evangelii Gaudium, we } \\
\text { would support, criticize, and suggest pastoral movements to develop Maria } \\
\text { Shrine of Annai Velangkanni. The inculturation can be found in this shrine } \\
\text { and become an effective evangelization. The management should be a system } \\
\text { which involves many parts to give a better service and increase the incultur- } \\
\text { ation with local cultures (Batak). }\end{array}$ \\
\hline
\end{tabular}

\section{PENDAHULUAN}

Sejak semula Yesus telah memberi perintah kepada para rasul. "Karena itu pergilah, jadikanlah semua bangsa murid-Ku" (Mat 28:19). Perintah ini telah dijalankan oleh Gereja selama berabad-abad lamanya. Berbagai cara telah dilakukan oleh Gereja baik secara konvensional maupun secara kreatif dan inovatif. Dalam tugas pewartaan itu, Gereja melibatkan budaya sebagai bagian dari fenomena manusia. ${ }^{1}$ Di sinilah terjadi proses yang disebut inkulturasi. Inkulturasi merupakan elemen integral dari pewartaan Injil. ${ }^{2}$ Dewasa ini, pewartaan Injil dan inkulturasi menjadi perhatian Gereja. Paus Yohanes Paulus II pernah menulis: "Iman yang tidak terinkulturasi adalah iman yang tidak diterima dengan utuh, yang tidak dipikirkan secara lengkap, dan yang tidak dihidupi dengan setiap". ${ }^{3}$ 
Salah satu usaha inkulturasi di Keuskupan Agung Medan saat ini adalah mewartakan Injl melalui sebuah bangunan yang sangat unik dan terkenal bernama Graha Maria Annai Velangkanni. Bangunan tersebut berada di Jalan Sakura III, MedanSumatera Utara. Keunikan dan keindahan bangunan ini telah tersiar ke mana-mana baik ke dalam maupun ke luar negeri. Graha Maria Annai Velangkanni mempunyai arsitektur Hindu-Mughal ${ }^{4}$. Dari kejauhan terlihat seperti kuil Hindu padahal bangunan tersebut adalah sebuah gereja Katolik.

Keindahan bangunan ini tidak hanya dapat dilihat dari luar. Di dalam bangunan ini terdapat berbagai ornamen dan simbol yang sangat menarik bagi para pengunjung. Setiap hari khususnya hari Sabtu dan Minggu, banyak pengunjung yang mendatangi tempat ini. Mereka berasal dari berbagai suku, agama, bahasa, dan budaya. Ornamen dan simbol itu tersebut bukan asal dibuat, tetapi mempunyai maksud dan tujuan pewartaan iman dan ajaran Katolik. Budaya India yang ditampilkan dalam bangunan ini mempunyai sejarah yang cukup panjang. Awalnya bangunan ini diperuntukkan untuk orang-orang India, tetapi dalam proses selanjutnya bangunan ini terbuka bagi semua orang. Penulis akan menjelaskan secara sekilas sejarah pendirian bangunan ini mulai dari asal-usul devosi kepada Bunda Maria Annai Velangkanni, masuknya orang-orang India ke Medan, pelayanan Gereja bagi orang India, hingga pendirian Graha Maria Annai Velangkanni. Pendirinya adalah Romo James Bharataputra, SJ. Usianya sudah 80 tahun dan telah sangat lama berkarya di Keuskupan Agung Medan. Sejak Graha Maria Annai Velangkanni didirikan pada tahun 2001 dan diresmikan tahun 2005 hingga sekarang, Romo James setia tinggal sendirian untuk mendampingi para pengunjung dan mengelola tempat ziarah tersebut. Penulis terdorong untuk mengapresiasi usaha-usaha beliau untuk menghadirkan sebuah tempat ziarah yang begitu megah di kota Medan seraya merefleksikan Graha Maria Annai Velangkanni secara teologis.

Tulisan ini didasarkan pada tesis yang berjudul "Keberadaan Graha Maria Annai Velangkanni sebagai Bentuk Pewartaan Injil secara Inkulturatif di Keuskupan Agung Medan”. Keberadaan Graha Maria Annai Velangkanni tidak bisa dilepaskan dari peran Romo James Bharataputra, SJ. Pengalaman rohani dan kontemplasi atas misteri penjelmaan (mysterium incarnationis) dalam Latihan Rohani St. Ignatius Loyola menjadi ide dasar untuk membangun Graha Maria Annai Velangkanni dan memperkenalkan devosi kepada Bunda Maria Sang Penyembuh (Mother of Good Health) kepada semua orang tanpa terkecuali.

Penulis merasa kagum akan keberadaan Graha Maria Annai Velangkanni yang dikunjungi oleh banyak orang. Siapa saja diperbolehkan untuk masuk tanpa dipungut biaya sepeser pun. Semuanya gratis. Para pengunjung terlihat mengalami sukacita, kegembiraan, dan ketenangan, berada di Graha Maria Annai Velangkanni. Pengalaman itu bisa dimaknai sebagai pengalaman perjumpaan dengan Allah. Untuk itu, Romo James menghadirkan beragam ornamen dan simbol agar iman Katolik semakin dimengerti dan dipahami oleh semua orang. Menjadi pertanyaan kemudian adalah sejauh mana bentuk bangunan Graha Maria Annai Velangkanni dengan segala ornamen dan simbol di dalamnya, dapat dimengerti oleh para pengunjung? Bagaimana model pewartaan Injil secara inkulturatif itu ditemukan dalam Graha Maria Annai Velangkanni? Apakah aset ini 
dapat dikembangkan oleh Gereja untuk pewartaan Injil dan inkulturasi?

Inilah yang akan diteliti oleh penulis dengan metode kualitatif dan kuantitatif (campuran). Metode kualitatif dilakukan dengan mengadakan wawancara dengan Romo James dan beberapa orang India yang sudah lama tinggal di Medan. Metode kuantitatif dilakukan dengan menyebarkan kuesioner atauangket secara acak untuk dijawab oleh para pengunjung. Selanjutnya, hasil penelitian itu dianalisa dan direfleksikan secara teologis berkaitan dengan pewartaan Injil, inkulturasi dan kesalehan yang merakyat. Penulis akan menyajikan refleksi teologis pribadi yang didasarkan pada Seruan Apostolik Paus Fransiskus Evangelii Gaudium ${ }^{5}$. Refleksi teologis tersebut akan mendorong penulis untuk menyajikan saran dan langkah pastoral yang perlu dilakukan oleh pengelola, Keuskupan Agung Medan, para pastor paroki, dan para pengunjung di Graha Maria Annai Velangkanni.

\section{DEVOSI KEPADA BUNDA MARIA ANNAI VELANGKANNI}

Kata "velangkanni" yang sekarang digunakan di Medan sebenarnya berasal dari kata vailankanni ${ }^{6}$. Vailankanni adalah nama sebuah kota di daerah Tamilnadu, India. Di sana ada sebuah basilika yang bernama Basilika Vailankanni Arockia Mathai dan sering disebut "Lourdes dari Timur" (Lourdes of East). Sebutan ini mau menunjukkan bahwa penghormatan kepada Bunda Maria juga dapat ditemukan di daerah Asia, bukan hanya di Barat. Gereja ini berada di tepi pantai Bengala $350 \mathrm{~km}$ sebelah selatan Madras dan 12 km sebelah Selatan Nagapattinam. ${ }^{7}$

Devosi kepada Bunda Maria berkembang di daerah Vailankanni sejak tahun 1500-an. Devosi ini dilatarbelakangi adanya kisah-ki- sah penampakan Bunda Maria. Salah satu kisah yang cukup terkenal adalah kisah penampakan Bunda Maria menampakkan diri kepada seorang anak yang lumpuh. Anak itu bertemu dengan seorang gadis yang sangat cantik memangku seorang bayi. Gadis itu meminta secangkir susu untuk bayi yang dipangkunya. Sebagai tanda terima kasihnya, gadis itu meminta bayinya untuk menyembuhkan anak lumpuh itu. Suatu mukjizat terjadi bahwa anak itu akhirnya bisa berjalan dan diutus pergi ke Nagapattinam dengan pesan agar baginya didirikan sebuah kapel. Ketika pesan itu disampaikan, orang-orang percaya bahwa yang menampakkan diri kepada anak lumpuh itu adalah Bunda Maria. Tanpa menunda-nunda orang Katolik dari Nagapattinam itu membangun sebuah kapel kecil sebagai penghormatan kepada Sang Perawan yang Terberkati. Di dalam kapel itu terdapat sebuah altar, tempat patung Bunda Maria yang sedang memangku Bayi Yesus diletakkan. Berita itu dengan cepat tersiar dan banyak orang yang datang berkunjung. Di sana terjadi beragam penyembuhan. Oleh sebab itu, Bunda Maria digelari Bunda Penyembuh dari Vailankanni (Our Lady of Good Health Vailankanni). ${ }^{8}$

Kisah ini sangat dikenal oleh orang-orang India khususnya mereka yang berasal dari daerah Nagapattinam sehingga devosi kepada Bunda Maria terus dipraktekkan kemana pun mereka pergi. Inilah yang melatarbelakangi penyebaran devosi ini di kalangan orang-orang India yang ada di kota Medan.

\section{MASUKNYA ORANG-ORANG INDIA KE MEDAN-SUMATERA UTARA}

Provinsi Sumatera Utara yang ada sekarang, sejak dulu sudah mempunyai hubungan yang baik dengan Asia Selatan selama lebih dari satu millenium. Prasasti Tamil di 
Lobu Tua dan Porlak Dolok merupakan bukti yang paling jelas menunjukkan relasi itu. Prasasti di Lobu Tua adalah prasasti dari tahun 1088 yang ditemukan pada tahun 1873. Prasasti di Porlak Dolok adalah prasasti dari Abad XIII yang ditemukan pada tahun 1920. Selain kedua prasasti itu, ada juga bukti lain berupa literatur-literatur Melayu dan tempat-tempat tertentu yang menandakan masuknya orang-orang India ke wilayah Provinsi Sumatera Utara. ${ }^{9}$

Sejak pertengahan abad XIX Medan sudah mengalami perkembangan yang cukup pesat di bidang ekonomi, sosial, budaya dan politik. Beberapa orang yang menjadi kongsi pemerintah memulai usaha di bidang perkebunan terutama tembakau, tebu, dan kelapa sawit. Perkebunan itu membutuhkan tenaga-tenaga buruh yang didatangkan dari Cina, India, Timur Tengah, dan Semenajung Malaka ke Medan. Inilah proses awal masuknya orang-orang India ke Medan dan membentuk komunitas di Kampung Keling di tepi kanan Sungai Deli, Medan. Pada tahun 1870-an komunitas Katolik di distrik Deli ada berjumlah 200 orang. Sampai sekarang komunitas orang-orang India masih ada di Kampung Keling. ${ }^{10}$

\section{PELAYANAN GEREJA KEPADA ORANG- ORANG INDIA DI MEDAN}

Pelayanan Gereja kepada orang-orang India dimulai oleh Pastor Ferdinand van Loon, OFM. Cap. Pada tahun 1914 Pastor Ferdinand van Loon, OFM.Cap dikirim oleh ordo untuk belajar bahasa Tamil ke Penang. Sepulang dari Penang pada tahun 1915, van Loon mendirikan gereja St. Antonius di bekas perkebunan milik Giugne. Kemudian, pada tahun 1922 dia memindahkan komunitas orang Tamil yang beragama Katolik dari Kampung Keling ke Kampung Kristen. ${ }^{11}$
Pastor Ferdinand van Loon memberikan perhatian lebih kepada orang-orang Tamil yang saat itu hidup dalam garis kemiskinan dan buta huruf. Dia mengurus mereka dengan mendirikan sekolah dasar dengan fasilitas asrama. Pada tahun 1930 sampai Perang Dunia II, misi tersebut berkembang pesat dengan segala budaya dan tradisi serta devosi yang mereka bawa dari India. Setiap tahun pesta Bunda Maria dan St. Antonius dirayakan dengan sangat meriah dan turun ke jalan-jalan. Pada Perang Dunia II orangorang Tamil ini sangat berjasa bagi Gereja Katolik. Merekalah yang menjaga dan mengurus gereja selama para pastor dan suster Belanda dipenjarakan oleh tentara Jepang. Segera sesudah Perang Dunia II selesai, Pastor van Loon yang sering digelari "Rasul Umat Katolik Tamil”, kembali ke Negeri Belanda dan meninggal pada tanggal 10 Februari $1947 . .^{12}$

Pelayanan kepada orang-orang India juga dilakukan oleh para suster-suster Santo Yosef yang datang ke Indonesia dari Negeri Belanda. ${ }^{13}$ Mereka disambut dengan sangat baik oleh Mgr. Brans dan Pastor van Loon OFMCap. serta beberapa orang suster SFD. Motto mereka adalah "Berkarya bagi Tuhan dalam Sesama”. Dengan motto ini para suster Santo Yosef melayani orang-orang yang miskin dan lemah terutama anak-anak dan kaum wanita. Anak-anak India yang orangtuanya bekerja sebagai buruh perkebunan, diasuh di asrama Daendels Straat (Asrama Hayam Wuruk sekarang) dan disekolahkan di Hollands Indische School. Mereka dididik dengan menggunakan bahasa Belanda. Tentu saja anak-anak itu mengalami kesulitan yang luar biasa. Sementara itu, ibu-ibu dipekerjakan di rumah-rumah untuk mencuci dan menyetrika. Lewat pelayanan para suster St. Yosef, orang-orang India mengalami perubahan. Anak-anak bersekolah dan 
ibu-ibu mendapat tambahan uang belanja. Gereja juga kelihatan semakin tertata rapi. Para suster itu tetap bersemangat dalam karya pelayanan meskipun mengalami kesulitan finansial dan keterbatasan bahasa. Selain menyelenggarakan kursus keterampilan puteri dan menjahit, para suster St. Yosef juga membuka sekolah taman kanak-kanak (Frobel). ${ }^{14}$

Ternyata misi di Medan cukup berkembang sehingga tenaga misionaris terus bertambah. Karena keterbatasan tenaga dari Belanda, maka para suster di Indonesia membuka novisiat untuk mendidik caloncalon suster pribumi. ${ }^{15}$ Sampai sekarang perhatian dan misi suster-suster Santo Yosef terhadap orang-orang India, masih tetap dipertahankan.

Pelayanan terkini kepada orang-orang India dilakukan oleh Romo James Bharataputra, SJ. Romo James Bharataputra lahir di Michaelpatnam, Tamilnadu India Selatan pada tangal 3 Juli 1938. Nama aslinya adalah Irudayam Singarayar Sebastian James (I.S.S. James). Orangtuanya adalah A.S. Irudayam Pillai dan K.S. Sandanammal. Dia mempunyai seorang saudari bernama Sister Rosalia Mary, O.S.M. dan tinggal di Tamilnadu. Keluarganya adalah pemeluk agama Katolik yang taat. Desanya terkenal memiliki tradisi hidup doa dan devosi yang kuat. Oleh sebab itu, sejak kecil anak-anak sudah dibiasakan untuk berdoa setiap hari, mendapat pendidikan iman Katolik, serta selalu berkumpul di depan Gua Maria. Maka, tidak mengherankan bahwa banyak biarawan-biarawati yang berasal dari Desa Michaelpatnam. ${ }^{16}$

Kebiasaan hidup doa sejak kecil dan kedekatan dengan biarawan-biarawati, mendorong James untuk bergabung dengan Serikat Yesus pada tanggal 30 Mei 1957.
Dia ditahbiskan menjadi imam Jesuit di Michaelpatnam India pada tanggal 27 Desember $1970 .{ }^{17}$ Setelah ditahbiskan menjadi imam, keinginannya menjadi misionaris begitu kuat sehingga dia berangkat ke Medan, Sumatera Utara. Pada waktu itu Uskup Agung Medan, Mgr. Ferrerius van den Hurk meminta dia untuk mendampingi komunitas orang-orang Tamil yang ada di Medan. Dia segera ditugaskan sebagai pastor rekan di Paroki St. Antonius Jl. Hayam Wuruk, Medan (1972-1983). ${ }^{18}$

Dalam tugas pelayanannya, pertama-tama Romo James mengusahakan pendidikan yang layak bagi orang-orang India. Dia mendirikan sekolah dasar yang diberinya nama "Karya Darma". Sekolah itu menjadi berkat bagi banyak orang tidak hanya orang India saja. Ratusan anak-anak dari keluarga yang sangat miskin dapat mengecap pendidikan dasar di sana. Selain bergerak di bidang pendidikan, Romo James juga berusaha untuk mengubah mentalitas orangorang India yang ada di Kampung Kristen. Dia mendorong mereka untuk bersosialisasi dengan masyarakat sekitar. Mereka ditantang untuk keluar dari Kampung Kristen yang selama ini menjadi zona nyaman mereka. Dengan demikian, mereka akan belajar, bekerja dan bertahan hidup. Ide tersebut tidak dengan mudah dapat diterima oleh orang-orang India. Tidak sedikit yang menentang dan memberontak. Mereka bertahan tinggal di Kampung Kristen dan tidak mau pindah. Hal ini menyusahkan hati Romo James tetapi dia tidak mau berhenti untuk melayani orang-orang India. Dia tetap berharap komunitas tersebut akan mengerti apa yang dia lakukan adalah demi kebaikan mereka. Pada bulan Juli 2000 dia diminta oleh Uskup Agung Medan Mgr. Pius Datubara untuk menjadi pelaksana pembangunan Graha Maria Annai Velangkanni di Tanjung 
Selamat Medan (2000-2005) dan sekaligus menjadi Rektor sejak tahun 2005 hingga sekarang. ${ }^{19}$

\section{KONTEMPLASI ROMO JAMES ATAS MISTERI PENJELMAAN DARI LATIHAN ROHANI SANTO IGNATIUS}

Sebagai seorang Jesuit, Romo James tentu saja tidak asing dengan Latihan Rohani Santo Ignatius dari Loyola. Latihan Rohani sudah menjadi bagian dari kehidupannya. Dari hasil wawancara (depth interview), diperoleh data bahwa Romo James terlebih dahulu mengadakan kontemplasi sebelum merancang bentuk bangunan Graha Maria Annai Velangkanni. Dia berusaha untuk terus-menerus membuka kemungkinan perubahan seturut dorongan Roh yang dirasakannya. Hasil kontemplasi itu diwujudkan dalam bentuk bangunan yang dapat dinikmati oleh banyak orang. ${ }^{20}$

Dalam kontemplasi tentang misteri penjelmaan, Romo James membaginya dalam tiga pendahuluan. Pendahuluan pertama adalah mengingat-ingat cerita yang harus dikontemplasikan tentang Ketiga Pribadi Ilahi memandang seluruh permukaan atau keliling bumi penuh dengan manusia. Manusia masuk ke dalam neraka akibat dosa-dosa mereka. Maka, Allah menjadi manusia untuk menyelamatkan umat manusia. Pendahuluan kedua adalah membayangkan luasnya permukaan bumi, di mana tinggal sekian banyak bangsa yang berbeda-beda. Pendahuluan yang ketiga adalah memohon pengertian yang mendalam tentang Tuhan yang menjadi manusia bagiku agar lebih mencintai dan mengikutiNya lebih dekat.

Selanjutnya, ada tiga tahapan kontemplasi misteri penjelmaan. Tahapan pertama adalah gambaran tentang manusia yang ada di bumi dengan bera- gam pakaian dan tingkah laku. Ada yang putih, ada yang hitam, ada yang hidup dalam perdamaian, dan ada yang hidup dalam peperangan. Semuanya menjadi satu. Ketiga Pribadi Ilahi bersemayam di surga dan memandang seluruh permukaan bumi dan segala bangssa yang hidup dalam kebutaan dan masuk ke dalam neraka. Dalam situasi inilah, Bunda Maria tampak dan malaikat memberi salam kepadanya. Tahapan kedua adalah gambaran tentang kejahatan orangorang di bumi yang melawan Allah. Allah menanggapinya dengan merencanakan penebusan demi keselamatan manusia. Tahapan ketiga adalah pribadi-pribadi Ilahi mengerjakan penjelmaan yang teramat suci. Muncul dalam bayangan bagaimana malaikat melaksanakan tugas menyampaikan Kabar Gembira dan Bunda Maria menyatakan keredahan dirinya (magnificat) serta berterima kasih kepada Keagungan Ilahi. Setelah melampaui ketiga tahapan ini, Romo James mengadakan suatu percakapan sambil memikirkan apa yang harus dikatakan kepada Ketiga Pribadi Ilahi atau kepada Yesus Kristus atau kepada Bunda Maria. Percakapan itu mendorong Romo James untuk menuruti apa yang muncul di hatinya dan mengikuti serta meneladan Allah yang mau merendahkan diri-Nya. ${ }^{21}$

\section{ORNAMEN-ORNAMEN DAN SIMBOL- SIMBOL SERTA MAKNANYA ${ }^{22}$}

Keberadaan Graha Maria Annai Velangkanni tidak bisa dilepaskan dari misteri penjelmaan yang dikontemplasikannya. Berbagai ornamen dan simbol diarahkan untuk mengungkapkan misteri tersebut. Allah hadir di tengah-tengah manusia dan menyapa semua orang tanpa kecuali. Sapaan itu ditampilkan melalui berbagai ornamen 
dan simbol yang dapat dilihat di Graha Maria Annai Velangkanni. Setiap ornamen dan simbol mempunyai makna dan arti yang dapat menghantar setiap orang mengalami perjumpaan dengan Allah dan memahami isi Kitab Suci.

Pintu gerbang Graha Maria Annai Velangkanni merupakan bagian dari bangunan yang dihiasi secara inkulturatif dengan rumah adat Batak Toba dan Karo. Romo James menyadari bahwa di Keuskupan Agung Medan ada tiga suku besar yaitu Batak Toba, Batak Simalungun dan Karo. Dua rumah adat yang ditempatkan pada bagian atas pintu gerbang mau menunjukkan bahwa mayoritas umat Katolik di Medan adalah suku Batak Toba dan Graha Maria Annai Velangkanni berdiri di wilayah di mana mayoritas umat Katolik adalah orang Karo. Selain itu, pada bagian tembok diukir relief berbagai suku bangsa dengan pakaian adat masing-masing. Hal ini menandakan bahwa Graha Maria Annai Velangkanni terbuka untuk segala bangsa, suku, bahasa, dan agama.

Bangunan utama terdiri dari dua lantai. Lantai atas yang terdiri dari menara tujuh tingkat dengan tiga menara berkubah adalah gambaran surga. Lantai bawah yang dihubungkan dengan jembatan layang merupakan gambaran bumi. Jalan aspal menuju Graha dan jalan layang menuju ke gereja melambangkan suatu pelukan Ilahi dan insani. Jalan aspal itu bagaikan manusia yang bersujud dalam segala kedosaannya datang menyerahkan diri kepada Allah. Kemudian kedua belah tangan Bunda Maria dalam gambaran jalan layang, merangkul manusia yang bersujud dan menghantarnya kepada Yesus Sang Putera. Makna dari jalan aspal dan jalan layang ini adalah barangsiapa masuk dalam rangkulan Maria akan menikmati janji Tuhan yakni keselamatan dalam diri Yesus dan memperoleh hidup yang kekal.
Di dalam gereja di lantai dua terdapat kutipan Kitab Suci yang berbunyi: "Datanglah pada-Ku, semua yang letih lesu dan berbeban berat. Aku akan memberikan kelegaan bagimu" (Mat 11:28). Kutipan ini dituliskan dalam empat bahasa: Bahasa Tamil, Bahasa Indonesia, Bahasa Inggris dan Bahasa Mandarin. Tujuan dari tulisan ini adalah mengajak semua orang untuk masuk dan merasakan kedamaian tinggal bersama Yesus di bait-Nya yang kudus.

Pada langit-langit gereja terdapat enam relief yang menggambarkan enam sakramen dalam Gereja Katolik yaitu Sakramen Baptis, Krisma, Perkawinan, Imamat, Tobat dan Pengurapan Orang Sakit (POS). Sakramen ketujuh adalah Sakramen Ekaristi yang dilambangkan dengan altar. Pada langit-langit gereja itu, ada juga empat gambar yang menceritakan keajaiban yang dilakukan oleh Bunda Maria di Vailankanni India. Keempat gambar itu menunjukkan bahwa devosi kepada Maria Annai Velangkanni sudah lama dikenal oleh orang-orang India dan kemudian diperkenalkan di kota Medan.

Ada tiga altar di panti imam yaitu altar Maria, altar Emmanuel, dan altar utama. Pada Altar Maria terdapat patung Maria. ${ }^{23}$ Altar Emmanuel berada di sebelah kiri altar utama. Altar ini sekaligus menjadi Tabernakel dengan gambar Hati Yesus yang Mahakudus. Altar utama berada bagian sentral dalam gereja. Meja altar dibentuk bagaikan akar pohon yang menyerupai Yesus yang tersalib. Lambang ini mengingatkan pengunjung bahwa kematian datang dari pohon akibat dosa Adam dan kehidupan baru datang dari pohon berkat wafat Yesus.

Inilah penjelasan dari beberapa bagian ornamen dan simbol yang ada di komplek Graha Maria Annai Velangkanni. Masih ada bagian-bagian lain yang belum dijelaskan da- 
lam tulisan ini. Namun demikian, kekayaan budaya sungguh-sungguh ditampakkan oleh Romo James untuk menggambarkan kisah-kisah dari Kitab Suci dan ajaran iman Katolik. Bentuknya yang unik menyimpan makna yang harus terus digali.

\section{TEMUAN DAN TANTANGAN PASTORAL DI GRAHA MARIA ANNAI VELANGKANNI}

Dalam meneliti pengaruh keberadaan Graha Maria Annai Velangkanni bagi pewartaan Injil di Keuskupan Agung Medan, penulis melalui tiga tahapan. Tahap pertama adalah observasi. Selama dua minggu penulis tinggal di Graha Maria Annai Velangkanni dan mengadakan pengamatan serta memimpin perayaan Ekaristi setiap hari kecuali hari Minggu. Tahap kedua adalah wawancara dengan Romo James Bharataputra, SJ dan beberapa pengunjung. Tahap ketiga adalah membuat kuesioner untuk dijawab oleh 100 orang responden secara acak (random). Hasil penelitian ini kami sajikan berdasarkan empat item yaitu identitas responden, kerohanian responden, kegiatan dan pengalaman di Graha Maria Annai Velangkanni, pengetahuan dan pemahaman akan ornamen-ornamen dan simbol.

Berdasarkan kuesioner yang diisi oleh para responden, ada 61 orang beragama Katolik dan 39 orang beragama bukan Katolik. Mayoritas pengunjungnya adalah kaum perempuan dengan tingkat pendidikan lebih dari separuh adalah lulusan SMA. Dari segi umur, mayoritas berusia 18-50 tahun. Dari segi pekerjaan, tidak ada yang dominan. Pekerjaannya bermacam-macam: mahasiswa, pegawai, guru, dan ibu rumah tangga. Dari segi suku, mayoritas pengunjung adalah orang-orang Batak (Toba, Karo, Simalungun). Mayoritas pengunjung adalah oang- orang Katolik baik dari wilayah Keuskupan Agung Medan mapun dari luar Keuskupan Agung Medan.

Dari hasil temuan ini penulis dapat menggambarkan bahwa kebanyakan pengunjung yang datang merupakan orang-orang yang sudah dapat menggunakan akal budi untuk menangkap arti dan makan ornamen dan simbol. Tingkat pendidikan mereka cukup memadai untuk itu. Dengan demikian, ornamen-ornamen dan simbol yang ditunjukkan oleh Romo James dapat dipikirkan dan diketahui bila diberikan penjelasan yang signifikan. Inilah salah satu kesempatan pastoral yang dapat dilihat oleh pengelola dalam memberikan penjelasan dan keterangan kepada para pengunjung.

Menilik sejarah pendirian Graha Maria Annai Velangkanni dan harapan Romo James, bangunan ini awalnya diperuntukkan sebagai tempat pertemuan orang-orang India yang ada di sekitar kota Medan. Dari hasil penelitian ternyata tidak banyak orang India yang datang ke tempat ini dan penulis mengalami keterbatasan bahasa untuk meminta mereka dalam pengisian kuesioner ini. Dari sini penulis menemukan masalah pastoral berkaitan dengan pelayanan kepada orang-orang India. Pelayanan tersebut belum menjadi perhatian pihak pengelola dan Keuskupan Agung Medan. Keberadaan orang India tidak secara langsung dikaitkan dengan Graha Maria Annai Velangkanni. Selama ini Romo James telah berusaha untuk melibatkan orang-orang India dalam pengelolaan dan pemeliharaan tempat ini. $\mathrm{Na}$ mun, perhatian itu dirasa oleh mereka tidak cukup sehingga ke depan Keuskupan perlu memikirkan perhatian dan pelayanan kepada orang-orang India serta mengembangkan pastoral bagi para pengunjung Graha Maria Annai Velangkanni. Mereka tetap perlu dili- 
batkan untuk merawat budaya India yang ada di Graha Maria Annai Velangkanni.

Kerohanian pengunjung akan turut mempengaruhi sikap mereka dalam memahami dan menangkap makna simbol dan ornamen di Graha Maria Annai Velangkanni. Dalam hidup keberagamaan orang Kristen, yang pokok adalah sikap batin bukan sikap lahiriah. Namun demikian, tanpa bentuk yang nyata komunikasi iman tidak mungkin terjadi. Sikap batin keagamaan seseorang harus ditunjukkan lewat tindakan dalam ibadat atau kegiatan-kegiatan rohani. Pengungkapan iman itu perlu untuk mengetahui penghayatan iman seseorang. ${ }^{24}$

Dari hasil penelitian tampak adanya ketimpangan hidup menggereja dan hidup bermasyarakat. Keaktifan hidup menggereja mempunyai persentase yang cukup tinggi $(54,1 \%)$, sementara keaktifan dalam kegiatan RT/RW sangat rendah (75,4\%). Dibutuhkan analisis sosial mengenai kehidupan iman dan kehidupan praktis umat. Penulis menduga bahwa pertanggungjawaban iman belum tampak dalam kegiatan-kegiatan kemasyarakatan. Romo James sungguh mengharapakan agar melalui Graha Maria Annai Velangkanni semua orang termasuk umat Katolik membangun persaudaraan yang sejati tanpa sekat-sekat agama, suku, bahasa, dan budaya. Semua orang menjadi satu di Graha Maria Annai Velangkanni. Gereja perlu mendorong umat untuk terlibat secara aktif dalam kehidupan menggereja dan bermasyarakat.

Penerapan Latihan Rohani Santo Ignatius dari Loyola sebenarnya tampak dalam kekayaan simbol dan ornamen yang ada di Graha Maria Annai Velangkanni. Pastoral simbol dalam konteks inkulturasi akan sangat membantu umat untuk semakin mengenal iman Katolik. Dari penelitian men- genai pengenalan akan makna ornamen dan simbol yang ada di Graha Maria Annai Velangkanni, penulis menemukan bahwa miniatur rumah adat Batak di bagian pintu gerbang masuk baru diketahui segelintir orang (26,2\%). Makna menara tujuh tingkat sebagai simbol surga hanya diketahui sepertiga pengunjung $(36,1 \%)$. Tiga kubah sebagai simbol Tritunggal Mahakudus diketahui oleh hampir separuh pengunjung (42,6\%). Gambar manusia yang bersujud dengan aspal sebagai tanda kehinaan diketahui hampir separuh pengunjung (49,2\%). Lukisan kisah penciptaan di dinding jalan layang menuju gereja diketahui separuh pengunjung (50,8\%). Lukisan tentang aneka sakramen dalam Gereja Katolik di langit-langit gereja diketahui lebih separuh pengunjung (59\%). Lukisan perjamuan malam terakhir untuk menggambarkan sakramen Ekaristi, diketahui dua per tiga pengunjung $(67,2 \%)$.

Dari persentase ini, dapat disimpulkan bahwa hasil kontemplasi Romo James atas Latihan Rohani St. Ignatius dari Loyola tentang misteri inkarnasi belum sepenuhnya dapat diketahui oleh para pengunjung. Ada beberapa lukisan, simbol dan ornamen yang sudah diketahui lebih dari separuh pengunjung. Namun demikian, perhatian perlu diberikan pada bagian ornamen dan simbol yang masih sulit diketahui oleh para pengunjung. Penjelasan itu akan sangat membantu mereka untuk memaknai misteri penjelmaan Yesus Kristus dalam berbagai lukisan dan simbol sebagai bentuk katekese iman. Kekayaan simbol dan ornamen yang ada tidak berhenti hanya pada keindahan yang memanjakan mata. Semua itu harus menghantar para pengunjung untuk mempunyai iman, pengharapan dan kasih. Sesuai dengan harapan Romo James, semua ornamen dan simbol bermuara pada Yesus Kristus. Penghormatan kepada Bunda Ma- 
ria diarahkan untuk sampai pada penghormatan kepada Yesus. Katekese harus terus diupayakan melalui pendampingan kepada para pengunjung khususnya kepada keluarga-keluarga Katolik.

Dari hasil penelitian diperoleh data mengenai kurangnya pemahaman dan pengetahuan para pengunjung akibat dari keterbatasan tenaga pendamping. Mereka diharapkan dapat memberikan penjelasan dan keterangan perihal makna ornamen dan simbol. Dalam pendampingan itulah, para pengunjung mendapat penjelasan tentang ajaran-ajaran Gereja dan kekayaan iman Katolik yang terkandung dalam aneka ornamen dan simbol di Graha Maria Annai Velangkanni.

Selain menyebarkan kuesioner kepada para pengunjung, penulis juga mewawancarai beberapa orang India beragama Katolik yang tinggal di kota Medan. Mereka mempunyai komunitas dengan nama Komunitas Santo Bonaventura ${ }^{25}$. Mereka mengungkapkan rasa bangga atas kehadiran Graha Maria Annai Velangkanni dengan ornamen-ornamen yang khas dari budaya India. Bangunan ini juga telah menjadi ikon di kota Medan dan dikunjungi oleh banyak orang. Dari hasil wawancara, penulis menyimpulkan bahwa orang-orang India yang beragama Katolik dan juga bukan Katolik merasa nyaman berdoa di Graha Maria Annai Velangkani. Devosi kepada Bunda Maria Penyembuh (Mother of Good Health) sebenarnya sudah lama mereka hidupi sebelum Graha Maria Annai Velangkanni dibangun. Devosi itu semakin kuat berkat keberadaan Graha Maria Annai Velangkanni. Di sana terdapat patung Bunda Maria yang unik dengan ciri khas orang India.

Mereka mengaku bahwa Graha Maria Annai Velangkanni mempunyai kharisma yang memancar sebagai "rumah bersama". Ada rasa nyaman untuk tinggal berlama-lama dan berdoa. Rasa hormat dan cinta yang semakin mendalam kepada Bunda Maria seringkali diungkapkan dengan menyentuh kaki atau tangan patung Bunda Maria Annai Velangkanni. ${ }^{26}$ Banyak doa dan permohonan yang terkabul di tempat ini. Maka, bagi orang-orang India yang beragama Katolik keberadaan Graha Maria Annai Velangkanni membawa sukacita besar.

Penelitian ini menghantar penulis untuk kembali melihat bagaimana pewartaan Injil dan inkulturasi serta devosi diserukan oleh Paus Fransiskus dalam dokumen Evangelii Gaudium. Beberapa poin penting diuraikan dan direfleksikan untuk mengafirmasi, mengkritik, dan memberi masukan bagi Romo James perihal keberadaan Graha Maria Annai Velangkanni.

\section{KERAGAMAN BUDAYA SEBAGAI ANUGERAH ALLAH}

Dalam Evangelii Gaudium, Bapa Suci menyinggung tentang keragaman budaya sebagai anugerah Allah. Gereja dapat mengungkapkan katolisitasnya yang sejati dan memancarkan wajah yang beraneka ragam dalam budaya-budaya setempat (EG. 116). Oleh sebab itu, nilai-nilai dari berbagai budaya diambil menjadi "pengantin perempuan yang memakai perhiasannya" (sponsa ornata monilibus suis). Inkulturasi ini akan menjadi suatu proses panjang yang berlangsung terus-menerus dan tidak pernah selesai (EG. 126).

Graha Maria Annai Velangkanni merupakan sebuah anugerah Allah bagi para pengunjung baik yang beragama Katolik maupun yang bukan Katolik. Keberadaannya unik karena memadukan arsitektur Hindu-Mughal. Bentuknya yang unik men- 
jadi satu model yang membuka cara baru memandang gereja sebagai tempat berdoa dan berjumpa dengan yang Ilahi. Selain itu, Graha Maria Annai Velangkanni mempunyai pintu gerbang yang dihiasi dengan tiga miniatur rumah adat Batak. Hal ini merupakan salah satu cara sederhana untuk menunjukkan bahwa mayoritas umat Katolik yang ada di Medan adalah orang-orang Batak. Untuk itu, budaya Batak perlu untuk dihadirkan.

Dari hasil penelitian penulis menemukan data bahwa ornamen-ornamen masih sangat menekankan budaya India sehingga budaya-budaya lain khususnya budaya Batak belum digarap dengan maksimal. Hal ini menjadi masukan bagi pengelola dan bagi Keuskupan Agung Medan untuk mendalami nilai-nilai spiritual budaya Batak. Dengan demikian, Graha Maria Annai Velangkanni dapat diharapkan menjadi "rumah bersama" bagi semua orang dari berbagai suku, agama, bahasa, dan budaya. Namun demikian, penulis setuju untuk tetap memperhatikan pelayanan pastoral kepada orang-orang India yang masih bertahan sebagai pemeluk agama Katolik. Sejauh ini penulis mengamati bahwa tidak banyak lagi orang India yang bertahan menjadi Katolik. Namun demikian, Romo James tetap memberikan pelayanan bagi mereka. Mereka dilibatkan dalam menata dan merawat Graha Maria Annai Velangkanni.

Proses pengembangan Graha Maria Annai Velangkanni tidak pernah berhenti sampai sekarang. Hal ini selaras dengan seruan Bapa Suci yang meminta agar usaha-usaha inkulturasi terus dilanjutkan karena membutuhkan proses panjang yang berlangsung terus-menerus (EG 126). Setiap orang didorong untuk terus mencari cara-cara pewartaan yang dapat merangkul semua orang dari berbagai suku, bahasa dan budaya.
Nilai-nilai budaya perlu terus digali sehingga orang-orang mampu melihat bahwa keberadaannya dihargai oleh Gereja melalui budaya yang diterima. Dalam konteks evangelisasi, inkulturasi bukan sekedar teori melainkan sesuatu yang dapat dirasakan oleh orang-orang setempat. ${ }^{27}$

\section{PEWARTAAN YANG BERCORAK DIALOGIS-EKLESIAL}

Dalam seruan apostoliknya, Paus Fransiskus memandang bahwa perjumpaan antara Injil dan budaya tidak selalu mudah direalisasikan. Inkulturasi hendaknya merupakan pengejawantahan dialog profetis karena sebuah konteks tidak selalu dengan mudah dapat terbaca pada permukaannya. Tidak semua unsur kebudayaan itu baik adanya. Pada saat yang sama ada beberapa hal dalam budaya yang harus dikritisi dan ditolak apabila tidak sesuai dengan nilai-nilai Injil (EG 73). Pengalaman mesti dihormati agar jangan sampai merancukan persepsi tentang suatu budaya. Dalam hal ini, corak dialogis dari pewartaan Injil sangat ditekankan (EG 133). Lebih lanjut, Paus Fransiskus meminta agar inkulturasi tidak hanya berhenti pada corak dialogis semata. Inkulturasi harus bercorak eklesial dalam arti menghormati nilai-nilai dan kebiasaan Gereja lokal, sekaligus terbuka pada koreksi oleh Gereja lokal lainnya dan masuk dalam pembicaraan kritis (EG 129).

Corak dialogis-eklesial inkulturasi menjadi rambu-rambu pewartaan Injil. Graha Maria Annai Velangkanni mempunyai misi pewartaan ke dalam (ad intra) dan misi pewartaan ke luar (ad extra). Kedua misi ini tidak selalu berjalan beriringan. Di sinilah, penulis menyampaikan kritik kepada Romo James dalam memahami budaya Batak. Sejauh pengetahuan penulis, sampai sekarang 
Romo James tidak bisa menggunakan salah satu bahasa Batak. Meskipun sudah berkarya lebih dari empat puluh tahun di Keuskupan Agung Medan, keterbatasan bahasa membuat beliau sulit berkomunikasi dengan orang-orang Batak. Ketika berjumpa dengan Romo James, kebanyakan pengunjung berbicara dalam bahasa Indonesia, bahasa India, dan bahasa Inggris. Hal ini menjadi tantangan dalam menghadirkan inkulturasi di tanah Batak.

Bagi Romo James, keterbatasan-keterbatasan yang ada bukan menjadi halangan untuk merangkul budaya-budaya yang ada di wilayah Keuskupan Agung Medan. Dia merangkul tenaga-tenaga ahli dari kalangan orang Batak untuk membangun Graha Maria Annai Velangkanni. Pembangunan itu tidak berhenti sampai sekarang. Selalu saja ada ide-ide baru nan kreatif yang membuat bangunan ini menjadi menarik bagi para pengunjung. Dialog yang dibangun oleh Romo James dengan budaya setempat terus diusahakan. Proses tidak pernah membohongi hasil. Seperti yang telah disampaikan sebelumnya, penulis memiliki kekaguman tersendiri saat melihat mayoritas para pengunjung yang datang adalah orang-orang Batak. Meskipun Romo James adalah seorang India dan tidak fasih berbahasa daerah, tetapi para pengunjung tidak mempersoalkannya. Mereka melihat sosok pribadi yang mau menghargai budaya dan membangun tempat berdoa yang indah.

Usaha-usaha membangun dialog dengan budaya setempat terus dilakukan oleh Romo James di Graha Maria Annai Velangkanni seraya memperkenalkan kebiasaan-kebiasaan yang ada dalam budaya India. Para pengunjung diminta untuk mengenakan pakaian yang pantas selama berada di Graha Maria Annai Velangkanni. Kebiasaan mele- paskan alas kaki sebelum masuk ke kapel Santa Maria dan gereja merupakan budaya yang tidak lazim bagi orang Batak. Tetapi, kebiasaan ini bisa diterima dan dilaksanakan oleh para pengunjung. Para pengunjung juga diingatkan untuk menjaga keheningan. Namun demikian, dialog dengan budaya setempat masih harus terus diusahakan bersama dalamm sebuah tim kerja.

\section{PEWARTAAN MERUPAKAN KARYA AL- LAH MELALUI JEMAAT}

Bapa Suci Fransiskus menyerukan agar karya pewartaan Injil tidak boleh dilihat sebagai usaha individu semata. Pewartaan terutama adalah karya Allah. Allah memanggil sebanyak mungkin orang untuk terlibat bekerja bersama dengan-Nya dan menuntun mereka dengan Roh-Nya. (EG. 12). Seruan Bapa Suci mendorongjemaat sebagai anggota Gereja untuk melibatkan seluruh hidupnya dalam karya pewartaan Injil. Pengalaman perjumpaan dengan Tuhan secara pribadi hendaknya ditampakkan dalam pelayanan dan pewartaan. Setiap orang dimampukan untuk mempertahankan semangat sukacita di tengah tugas perutusan itu dan ambil bagian dalam sejarah keselamatan.

Graha Maria Annai Velangkanni sebenarnya belum lama berdiri. Bangunan ini dibangun dalam kurun waktu empat tahun (September 2001- 2005). Bangunan ini baru berusia lima belas tahun lebih. Banyak perubahan yang terlihat dari bentuk awal pendirian hingga sekarang. Romo James mengakui bahwa hampir semua biaya pembangunan Graha Maria Annai Velangkanni berasal dari bantuan donatur hingga selesai. Tanpa berhitung-hitung mengenai biaya, Romo James melihat semua karya pelayanannya didedikasikan untuk Keuskupan Agung Medan. Meskipun selama ini banyak 
orang melihat bahwa pembangunan Graha Maria Annai Velangkanni menjadi tanggung jawab Romo James seorang diri, namun Romo James menghendaki agar pada waktunya pihak Keuskupan melanjutkan karya yang telah dimulainya.

Romo James menyadari bahwa usaha-usaha pewartaan melalui Graha Maria Annai Velangkanni tidak akan pernah selesai. Karya yang dulunya dimulai sendiri oleh Romo James harus menjadi karya bersama dan karya jemaat. Seluruh organ Keuskupan harus ikut ambil bagian di dalamnya. Umat juga perlu dilibatkan untuk semakin mengenal, mendalami, memahami makna ornamen dan simbol serta usaha-usaha inkulturasi yang ada di dalamnya.

\section{PEWARTAAN BERDIMENSI SOSIAL}

Paus Fransiskus mengharapkan agar agama tidak hanya dimasukkan dalam ruang batin kehidupan pribadi tanpa kepedulian akan perkembangan yang sehat dalam hidup sosial dan masyarakat. Sebaliknya, agama harus membuat manusia prihatin dengan peristiwa-peristiwa yang terjadi di tengah-tengah masyarakat (EG 183). Ketika Gereja hadir di tengah masyarakat dan budayanya maka mau tidak mau Gereja harus berani terluka, sakit dan kotor karena telah pergi ke luar ke jalan-jalan daripada hidup terkurung dan tergantung pada keamanan dan kenyamanan sendiri (EG 49).

Gagasan tentang pendirian Graha Maria Annai Velangkanni ikut juga dipicu oleh situasi Indonesia pada tahun 1997-1998 akibat krisis ekonomi. Negara dalam keadaan "sakit". ${ }^{28}$ Romo James merasa terpanggil untuk menawarkan "obat yang mujarab" untuk merajut kembali persatuan dan kesatuan bangsa. Dia merasa bahwa kehadiran Gereja harus menjadi solusi atas situasi negara dan penduduknya. Kehadiran Graha Maria Velangkanni mengundang banyak orang untuk bersama-sama mengalami kebaikan Tuhan. Keragaman budaya bukanlah pemisah anakanak bangsa, melainkan kekayaan yang harus diterima dalam perbedaan. Iman yang otentik tidak pernah hanya mementingkan kenyamanan pribadi. Iman itu mendorong setiap orang untuk keluar mengubah dunia, menyampaikan nilai-nilai baik, dan mengusahakan langkah-langkah baru bagi dunia (EG 183).

Upaya-upaya ini dilakukan untuk menyembuhkan masyarakat dari suatu penyakit yang membuatnya lemah dan mudah frustrasi serta krisis-krisis baru. Perhatian dan kasih Gereja dapat diarahkan kepada orang-orang kecil yang miskin dan dipinggirkan. Graha Maria Annai Velangkanni terbuka untuk semua orang dari berbagai golongan. Tidak ada larangan bagi orang miskin untuk masuk dan tak ada pengkhususan bagi orang kaya untuk datang. Semua diterima dengan tangan terbuka.

\section{DEVOSI SEBAGAI BUAH INKULTURASI INJIL}

Menurut Paus Fransiskus, devosi ${ }^{29}$ memampukan umat Allah melihat bagaimana iman sekali diterima, mewujud dalam kebudayaan dan senantiasa diteruskan. Kesalehan yang merakyat menampakkan kehausan akan Allah sehingga orang-orang mampu bersikap murah hati dan rela berkorban serta berani menjadi saksi (EG 123). Salah satu bentuk pewartaan Injil yang konkret dapat dilakukan oleh orang-orang yang dibaptis adalah berjalan menuju tempat-tempat suci, mengambil bagian dalam kesalehan yang merakyat, membawa anak-anak dan mengajak orang lain ke tempat-tempat suci. aksi-aksi semacam itu sudah merupakan tin- 
dak evangelisasi (EG 124). Di samping itu, Bapa Suci juga mengingatkan agar di negara-negara di mana kekristenan adalah minoritas, Gereja Partikular harus secara aktif memajukan setidak-tidaknya bentuk awal inkulturasi untuk mewartakan Injil dengan berani dan kreatif (EG 129). Kesalehan yang merakyat itu diungkapkan dengan simbol-simbol, bukan dengan kata-kata semata. Efeknya adalah mendorong Umat Allah untuk keluar dari dirinya dan menjalani peziarahan (EG 124). Dengan keluar dari dirinya, mereka menghargai kehidupan seperti ibu yang merawat anak-anaknya yang sakit dengan tetap erat memegang rosario dan menyalakan sebatang lilin di depan patung Bunda Maria yang diarahkan pada patung Kristus yang tersalib (EG 125). Kesalehan yang merakyat disadari sebagai buah inkulturasi Injil yang menjadi kekuatan bagi pewartaan Injil secara aktif dan kreatif.

Sebagai satu bentuk pewartaan Injil, Graha Maria Annai Velangkanni menawarkan satu bentuk devosi yang sudah dikenal oleh orang-orang India yakni devosi kepada Bunda Maria Penyembuh (Lady of Good Health). Dari hasil penelitian diketahui bahwa mayoritas pengunjung sudah mengetahui kisah penampakan Bunda Maria di Vailankanni India dan gelarnya sebagai Bunda Penyembuh. Sampai sekarang, setiap hari Sabtu sore doa rosario bersama untuk menghormati Maria Bunda Penyembuh, 30 menit sebelum perayaan Ekaristi dimulai. Sejauh ini kelihatan bahwa belum banyak umat yang hadir dan berpartisipasi. Namun pelan-pelan umat semakin bertambah terutama berkat kehadiran beberapa suster KSSY. Segala ornamen dan simbol Graha Maria Annai Velangkanni, devosi kepada Bunda Maria, perjumpaan dengan banyak orang, kiranya dapat mendorong siapa saja untuk mengambil bagian dalam karya pewartaan Injil dan hidup dalam sukacita.

\section{RELEVANSINYA UNTUK KEUSKUPAN AGUNG MEDAN}

Refleksi teologis atas pewartaan Injil dalam dokumen-dokumen Gereja sejak Konsili Vatikan II menunjukkan perhatian khusus terhadap kebudayaan setempat khususnya Gereja Asia. Aktor utamanya adalah Gereja Lokal. ${ }^{30}$ Keberadaan Graha Maria Annai Velangkanni dari sudut pandang dokumen-dokumen tersebut mendapat dukungan untuk terus dikembangkan. Graha Maria Annai Velangkanni sebagai bentuk pewartaan Injil kiranya dapat membantu Keuskupan Agung Medan untuk mengefektifkan karya-karya pewartaan Injil, inkulturasi dan devosi.

Graha Maria Annai Velangkanni merupakan satu bentuk pewartaan Injil secara inkulturatif di Keuskupan Agung Medan karena memasukkan unsur-unsur kekristenan dalam bentuk ornamen dan simbol ke tengah-tengah umat Katolik yang mayoritas adalah suku Batak. ${ }^{31}$ Tidak banyak unsur budaya Batak yang ada di sana. Namun, orang Batak bisa menerima kehadiran Graha Maria Annai Velangkanni. Setelah berkunjung ke Graha Maria Velangkanni, tidak sedikit orang yang mengalami kegembiraan dan sukacita serta memperoleh kesembuhan dan kekuatan iman. Devosi kepada Santa Perawan Maria dan orang-orang kudus semakin dikenal oleh banyak orang termasuk orang-orang Protestan. Hidup dan karya Romo James dapat dilihat sebagai bentuk kesaksian iman akan pertolongan dan perlindungan Bunda Maria. Hal ini akan sangat bergunan untuk menjelaskan iman Katolik tentang Bunda Maria kepada saudara-saudara yang beragama Kristen Protestan. Devosi harus terus digalakkan di Keuskupan Agung Medan seraya membangun dialog dengan 
penganut agama lain. Agar tidak salah dimengerti, devosi-devosi yang dikembangkan hendaknya tertuju pada perayaan Ekaristi dalam mempersiapkan hati seluruh umat. ${ }^{32}$ Dengan berbagai cara Gereja juga diharapkan mampu mereformasi banyak cara dan kebiasaan yang selama ini dianggap sudah tidak memadai dengan zaman sekarang. Gereja perlu keluar untuk menawarkan kehidupan Yesus Kristus kepada semua orang dengan penuh sukacita ${ }^{33}$

\section{PENUTUP}

Penelitian ini masih akan terus dikembangkan untuk mengembangkan pewartaan Injil dan inkulturasi di Keuskupan Agung

\section{CATATAN AKHIR}

1 Aylward Shorter, Evangelization and Culture, London: Geoffrey Chapman, 1994, 28.

2 Aylward Shorter, Evangelization and Culture, 29.

3 "A faith, which has not become inculturated is a faith which has not been fully received, which has not been completely thought through, which has not ben faithfully lived". Fr. Jacob Theckanath, "Evangelization and the Asian Face of Jesus" dalam Fr. Saturnino Dias (ed), Evangelisation and Inculturation (Mumbai: Pauline Press, 2001), 167.

4 Mughal adalah nama kekaisaran besar Muslim di Anak Benua India. Kekaisaran ini didirikan oleh Babur pada tahun 1526. Kekuasaan Mughal meliputi seluruh Inid kecuali daerah selatan jauh. Masa keemasan kekaisaran ini berlangsung dari tahun 1556-1707. Menjelang pertengahan abad XVIII, kekaisaran ini semakin melemah dan akhirnya hancur pada tahun 1858 oleh tentara Inggris. John L. Esposito (ed.) Ensiklopedi Oxford: Dunia Islam Modern. Diterjemahkan dari The Oxford Encyclopedia of the Modern Islamic World oleh Eva Y.N. dkk. (Bandung: Penerbit Mizan, 2001), 82-83. Selama ini dalam berbagai tulisan, arsitektur Graha Maria Annai Velangkanni sering disebut Indo-Moghul. Jadi, yang benar sebagai terjemahan bahasa Indonesia adalah arsitektur Hindu-Mughal.

5 Sukacita Injil memenuhi hati dan hidup semua orang yang menjumpai Yesus. Paus Fransiskus, Evangelii Gaudium: Sukacita Injil, terj Dokpen KWI (Jakarta: Departemen dan Penerangan Konferensi Waligereja Indonesia, 2015), 7.

6 Kata ini dapat digunakan untuk menunjuk pada sebuah sungai yang bernama Sungai Vellaiar di India. Secara etimologis, kata vailankanni merupakan gabungan dari vellai dan kanni. Kanni mempunyai tiga arti yang berbeda yaitu perempuan muda (perawan), jebakan, dan selokan kecil (vaaikkal dalam bahasa Tamil). Selain dari etimologisnya, vailankanni juga diartikan sebagai kota pelabuhan yang ramai dikunjungi oleh para pelaut Portugis dan pelaut-pelaut dari berbagai negara. A. Arokianathan, Vailankanni as Tourist and Pilgrimage Centre (Tiruchirappalli: Department of History St. Joseph's College, 2006), 30 .
Medan. Penulis mencoba untuk menunjukkan bahwa keberadaan Graha Maria Annai Velangkanni efektif bagi pewartaan Injil secara inkulturatif bagi orang-orang India beragama Katolik maupun bagi para pengunjung bukan India, seraya memperhatikan beberapa masukan bagi pengelola, pihak Keuskupan Agung Medan dan para pastor paroki untuk membantu para pengunjung dalam memahami ajaran iman Katolik yang terdapat dalam berbagai ornamen dan simbol. Ketika model ini diterima oleh banyak orang, Gereja perlu memikirkan dan mencari kekhasan budaya setempat agar Graha Maria Annai Velangkanni tetap bertahan dalam konteks pewartaan Injil di Keuskupan Agung Medan.

7 A. Arokianathan, Vailankanni as Tourist and Pilgrimage Centre, 28.

8 A. Arokianathan, Vailankanni as Tourist and Pilgrimage Centre, 51-53.

9 Daniel Perret, "Graha Maria Annai Velangkanni: une église d'inspiration indienne à Medan, Sumatra Nord" Archipel 82 (2011): 115 .

10 Daniel Perret, "Graha Maria Annai Velangkanni: une église d'inspiration indienne à Medan, Sumatra Nord", 116-118.

11 Daniel Perret, "Graha Maria Annai Velangkanni: une église d'inspiration indienne à Medan, Sumatra Nord", 118.

12 Kutipan ini diambil dari tulisan Mgr. A.G. Pius Datubara dalam Buku Proposal Pembangunan Graha Maria Annai Velangkanni tanggal 1 April 2004.

13 Ada lima orang suster Santo Yosef dari Belanda yang memulai karya pelayanan kepada orang-orang India di kota Medan yaitu Sr. Anselma Geerts, St. Alexia Beemer, Sr. Modesta Giesbers, Sr. Anicetha Okkersen, Sr. Valeria Wiemen, dan Sr. Odulfa Goedhart. Mereka tiba di Pelabuhan Belawan pada tanggal 28 Januari 1931. Tim Buku Kenangan Yubileum 75 Tahun KSSY di Indonesia, Jejak Cinta Sang Citra (Medan: t.p., 2006), 10 .

14 Tim Buku Kenangan Yubileum 75 Tahun KSSY di Indonesia, Jejak Cinta Sang Citra, 10-12.

15 Tim Buku Kenangan Yubileum 75 Tahun KSSY di Indonesia, Jejak Cinta Sang Citra, 21.

16 Gatot H. Sinulingga, "James Bharataputra: Seorang Pemimpi yang Ulung” (Tidak Dipublikasikan), 1.

17 Fr. James Bharataputra, "Graha Maria Annai Velangkanni Medan Indonesia" (Tidak Dipublikasikan), 5.

18 Gatot H. Sinulingga, "James Bharataputra: Seorang Pemimpi", 4.

19 Fr. James Bharataputra, "Graha Maria Annai Velangkanni Medan Indonesia", 7-8.

20 Wawancara ini diadakan pada tanggal 7 Agustus 2017 pukul 21.00 WIB di depan Graha Maria Annai Velangkanni. Romo James bersedia meluangkan waktu untuk diwawancarai sesudah makan malam. 
21 Hasil kontemplasi ini dituliskannya dalam sebuah teks dan diberikan kepada penulis pada tanggal 8 Januari 2017 di Graha Maria Annai Velangkanni.

22 Fr. James Bharataputra, "Graha Maria Annai Velangkanni Medan Indonesia", 31-50.

23 Patung ini datang di luar dugaan karena tiba di bandara Polonia Medan dari Madras-India, satu jam sebelum perayaan pesta Kelahiran Bunda Maria dimulai. Patung tersebut sudah jauh-jauh hari sebelumnya dipesan tetapi dua kali selalu gagal dalam proses pengiriman. Akhirnya, tanpa diduga pada tanggal 8 September 2001 patung itu muncul di Bandara Polonia Medan dan pihak bandara meminta Romo James untuk segera mengambilnya.

24 Konferensi Waligereja Indonesia, Iman Katolik: Buku Informasi dan Referensi, (Yogyakarta: Kanisius dan Jakarta: Obor, 1996), 162-164.

25 Dalam wawancara disebutkan bahwa Komunitas Santo Bonaventura sudah ada lebih dari 25 tahun, Anggotanya terdiri dari orang-orang India beragama Katolik yang berdomisili di sekitar kota Medan. Setiap minggu mereka mengadakan pertemuan, Sesekali mereka berkumpul di Graha Maria Annai Velangkanni untuk merayakan momen-momen istimewa dalam budaya India seperti upacara Deepavali.

26 Dari hasil wawancara penulis mengetahui bahwa dalam budaya India tindakan menyentuh kaki atau tangan patung merupakan ungkapan penghormatan yang sangat

\section{DAFTAR RUJUKAN}

Arokianathan, A. Vailankanni as Tourist and Pilgrimage Centre. Tiruchirappalli: Department of History St. Joseph's College, 2006.

Bharataputra, Fr. James. "Graha Maria Annai Velangkanni Medan Indonesia” (Tidak Dipublikasikan),.1-50.

Boelaars, Huub J. W. M.Indonesianisasi: Dari Gereja Katolik di Indonesia menjadi Gereja Katolik Indonesia. Yogyakarta: Kanisius, 2005.

Dias, Saturnino.Evangelisation and Inculturation. New Delhi: Pauline Publications, 2001.

Fransiskus, Paus. Evangelii Gaudium. Sukacita Injil: Seruan Apostolik Paus Fransiskus 24 November 2013. Diterjemahkan oleh F.X. Adisusanto dan Bernadeta Harini Tri Prasasti. Jakarta: Departemen dan Penerangan Konferensi Waligereja Indonesia, 2015. mendalam dan ucapan terima kasih atas permohonan yang terkabul. Orang India yang datang ke Graha Maria Annai Velangkanni selalu menyempatkan diri untuk menyentuh kaki atau tangan patung Bunda Maria.

27 James H. Kroeger, Asian Dynamic Local Churches: Serving Dialogue and Mission, (Bengaluru: Dharmaram Publications, 2014), 73.

28 http://www.seasite.niu.edu/indonesian/reformasi/krisis ekonomi.html diakses tanggal 27 Oktober 2018 pukul 18.30 WIB

29 Penulis menggunakan istilah devosi untuk menyebut kesalehan yang merakyat.

30 James H. Kroeger, Asian Dynamic Local Churches: Serving Dialogue and Mission, 51.

31 Menurut Hub Boelaars 97 \% umat Keuskupan Agung Medan adalah etnis Batak dengan perincian 77\% Batak Toba, $13 \%$ Batak Karo, 6\% Bata Simalungun, dan 2\% Batak Pakpak-Dairi. Hub Boelaars, Indonesianisasi: Dari Gereja Kaotlik di Indonesia menjadi Gereja Katolik Indonesia, (Yogyakarta: Kanisius, 2005), 223.

32 Nico Prasadja, "Maria dalam Kehidupan Devosional", dalam Kehidupan Devosional, ed. Frans Harjawiyata, OCSO (Yogyakarta, Kanisius, 1993), 102.

33 R.F. Bhanu Viktorahadi, Menjadi Gereja yang Bergelimang Lumpur: Telaah Singkat Anjuran Apostolik Paus Fransiskus Evangelii Gaudium (Yogyakarta: Kanisius, 2015), 42.

Harjawiyata, Frans (ed.). Kehidupan Devosional. Yogyakarta: Kanisius, 1993.

Kroeger, James H., Asian Dynamic Local Churches: Serving Dialogue and Mission. Bengaluru: Dharmaram Publications, 2014

Perret, Daniel. "Graha Maria Annai Velangkanni: une église d'inspiration indienne à Medan, Sumatra Nord" Archipel 82, 115-136.

Sinulingga, Gatot."James Bharataputra: Sang Pemimpi yang Ulung" (Tidak Dipublikasikan), 1-8.

Shorter, Aylward. Evangelization and Culture. London-New York: Geoffrey Chapman, 1994.

Viktorahadi, R.F Bhanu.Menjadi Gereja yang Bergelimang Lumpur: Telaah Singkat Anjuran Apostolik Paus Fransiskus Evangelii Gaudium. Yogyakarta: Kanisius, 2015. 